\title{
The Paradox of Professionalism in English Further Education: a TLC-FE Project Perspective
}

\author{
Denis Gleeson and David James. DRAFT ONLY.
}

\begin{abstract}
This paper examines the shifting nature of FE professionalism through the lenses of the TLC-FE project. Despite over a decade of market and managerial reform professionalism in FE remains an elusive and paradoxical concept. With some notable exceptions there exists little official data or research evidence of who its practitioners are, their dispositions or how they define professionalism in the contested contexts of their work (Foster, 2005). In addressing this neglected issue, albeit in a brief fashion here, the paper engages with wider debate concerning the culturally oriented nature of FE practice, as it mediates contradictory policy-practice agendas, at college level (Gleeson et al, 2005; Wallace \& Hoyle, 2006). It contrasts with a prevailing public management discourse that seeks to modernize and manageralise FE professionals whilst displaying little understanding of their current practice, or the neo-liberal conditions in which they work. Drawing on the narratives of experienced practitioners participating in the TLC-FE project (2001 - 2005) the paper explores their perceptions and experiences of professionalism through cultures of learning that simultaneously enhance and restrict their professional room for manoeuvre.
\end{abstract}

\section{The Paradox of Professionalism in English Further Education: a TLC-FE Project Perspective}

\section{Introduction}

This paper focuses on renewed interest in the way professionalism is being reworked from within and outside the changing conditions of FE practice. In so doing it engages with wider research interest into the nature of public sector professionalism as a vehicle of market modernization, or as an agent of social and democratic renewal. Recent research, notably in the field of 'new' public management, points to a range of factors that characterise the reconfiguration of professionalism across a range of health, education, welfare, social care and children’s provision (Clarke, 2006). These include:

- performance management and workforce reform (audit \& inspection)

- private-public partnerships in service delivery

- public choice agendas driven by key stakeholders

- interagency provision of public services

(see Simmons et at, 2006)

Though the meaning of such terms is ambiguous and generates different understanding, reaction and response in $\mathrm{FE}$ and other fields, they convey powerful structure and agency signals regarding the funding, provision and professional delivery of public services at organizational level. In the context of UK public sector reform these benchmarks increasingly define the detailed delivery of new public management by professionals whose will be measured, audited and inspected on the basis of their ability to meet prescribed targets (Newman 2001). In this context the shift from 'old’ public management, based on 
municipal bureau professionalism to 'new' public management - driven by market competition and public choice - embraces a quite different concept of public service: one that is managed, brokered and mediated by professionals in highly competitive and contested market situations. In this sense the complexity of FE as a 'case in point', though different from a school, hospital, health centre, clinic or welfare office, operates along similar lines of new public management, where practitioners become regarded as licensed deliverers of nationally produced materials, targets and provision( licensed rather than as trusted public professionals( Coffield et al 2005).

Recent research across a range of public provision points to increasing casualisation, work intensification and deprofessionalisation among professionals that includes a blurring of management and practitioners roles that involve greater flexibility. Yet in between such different notions of flexibility and permeability two contrasting views of professionalism predominate. The first perceives the professional as subject to external rules and constraints and, the second, as agents with power to define their own conditions of work. While the former denotes issues of structure (professionalism), in terms of how the professional is conditioned by material changes in working practices, the latter focuses on agency in the way professionals construct meaning and identity ( professionality e.g. through resistance, compliance, creative engagement) in the contradictory conditions of their work (Hoyle \& John, 1995; Ball, 2003).

The reified nature of such dualism between agency and structure is reflective of wider social science thinking that has led to polarized camps of theorists who either subscribe to a deterministic view that elevates structure over action or follow a voluntaristic perspective that privileges subjective agency (Gleeson \& Knights, 2006). This paper, however, is less concerned with resolving such dualism, as with discussing the way that their mediation is reflected in FE professional practice that facilitate political transformations that might advance forms of social as well as democratic professionalism and accountability. The objective is not to reconcile the dualism between agency and structure in the sense of Giddens (2000) or Blair's 'third way' (equating principles of social justice with those of the market: see Blair 1998), but rather to illustrate its 'mediation' (brokerage and trade-offs) through cultures of FE professional practice.

One argument for taking a cultural perspective in the TLC project is one of an interest in interdisciplinarity. Another derives from the work of Bourdieu( 1990) and a broader interest in situated learning (Lave \& Wenger, 1991). From the outset the TLC project held a strong collective view of the need for a relational understanding of professional knowledge as it derives from learning that takes place in formal and non-formal settings. At the same time the project put in place a design that relies heavily on practitioner participation and engagement. According to James \& Diment (2003) Bourdieu's concepts of habitus and field are key concepts in the TLC project that offer a distinctive view of learning cultures. They argue, for example, that habitus 'names' the characteristic disposition of the social subject and is deeply ingrained in habits of behaviour, feeling and thought. It also engages with the 'field' which is conceptualized as a structured system of social relations - in this case FE's relationship with society at micro and macro level - that interconnect agency and structure. The dialectical nature of such relationships allows the project to examine how certain sets of assumptions prevail in various learning situations, how they inform the practices of tutors, students, managers, employers and others, and how such practices contribute to the maintenance of particular learning culture (James \& Diment, 2003). 
practitioners are, how they construct professional meaning in their work and what, if any, new constrictions of professionalism are emerging as a result. The main focus is on the way FE professionals position themselves in and around various 'creative tensions' in the diverse contexts of their work. This involves how they understand, interpret and intervene in contradictory conditions that simultaneously enhance or restrict their professional practice. Accordingly the sections which follow provide a brief insight into how the TLC project has taken aspects of this cultural analysis forward. The first part of the paper explores different dimensions of how participants become practitioners in FE and the significance of 'flexibility' in their lives and work. The middle sections go on to examine how their professional dispositions and practices are played out through various processes of 'mediation' followed by a final consideration of the possibilities and limitations of the approach adopted.

\section{Getting in -becoming a practitioner in FE}

The TLC participating tutors' backgrounds illustrates something of the range of ways in which people become FE practitioners, confirming the widely-held perception that many FE practitioners begin their careers in further education with no formal training or background in teaching. Many never envisaged 'professional' careers, let alone in teaching, and some 'slipped' into the role through a range of unforeseen and unplanned events. Most had technical skills and qualifications, and many had substantial industrial, commercial or public sector experience directly related to what they were teaching. In many cases, former trade and occupational identities remained important and were called upon in a variety of ways (Venables, 1967; Gleeson and Mardle, 1980), though we also saw examples of the new 'learning professional', Guile and Lucas's term for the newer categories of FE worker that operates across academic and vocational divisions (Guile and Lucas, 1999). The diversity of tutors in many FE colleges is itself an important and distinctive feature of the learning culture that often goes unrecognised outside a sector described by Lucas (2004) as polycontextual in terms of the complexity of its provision.

Rachel, who had a successful career in the travel industry, spoke of 'sliding' into FE following a divorce and a wish for a fresh start. Once teaching, she gained both the City and Guilds 730 and the Certificate in Education (FE) qualifications through part -time study. Even so, she talks of the decision as a 'pragmatic' one: 'It's not a vocation for me and in fact if I didn't have the children I don't think I'd be here today'. For Paul, who taught photography, the decision to teach in FE was both vocational and pragmatic at the same time. He first of all did a small amount of evening class teaching alongside his work as a professional photographer, and found it enjoyable and rewarding. Within a few years he decided to teach full time, and to do what he called 'photography for me' alongside it. His income from teaching meant that it did not matter very much whether or not he sold the work he was producing and exhibiting. John started teaching when the college needed urgent cover for a particular area of work in which he was skilled and knowledgeable. At the same time his work in electrical appliance repair had begun to decline, and he consciously 'fished' for more teaching:

'I got to know a few people... and so eventually I sort of spent time sitting on the boss's doorstep, 'til he knew me well enough and I got a yearly contract, and then a full -time contract'.

Many new FE practitioners experience what we might term the 'long interview', where the individual starts with a few part-time hours, and, having established a link with a college, 
is offered more work or a full-time post after a period of months or years. Gwen recalls making a difficult decision to leave a secure, full-time office job in order to take up an insecure, part -time one in FE teaching:

'(I thought) shall I take a chance, because you can't get a job at any of the colleges, well certainly not in our faculty, you can't just get a full-time j ob off the streets. You have to be tried and tested. So I gave up my [full -time, secure] job and went part -time'.

Gwen then worked part- time for two years, at three different colleges, before being offered the full -time post that she had wanted all along.

These recruitment processes have been an established part of FE practice for a long time, and reflect the sector's wide range of purposes (Foster, 2005), its entrepreneurial nature and its multi-faceted links with a wide range of workplaces and stakeholder interests. Compared to schools, colleges live with a high degree of uncertainty about demand for their services from one year to the next (and sometimes over a much shorter timescale) as they respond to market fluctuations and shifts in policy. In recognising these features of the context, it is no surprise that the recruitment of staff who teach is a process often characterised by informality and uncertainty, in which 'flexibility' is a key asset (Edwards et al, 2001). There are clear benefits for colleges, and sometimes to individual practitioners too. Yet these come at a high price. The widespread use of fractional and temporary contracts has laid down distinctions between core and peripheral staff. Together with the proliferation of job titles in recent years and the low morale engendered by a lack of parity of esteem and reward with other parts of the education system, this contributes to the 'casualisation' and 'careerlesness' of the FE workforce (Mackney, 2004). In one of our learning sites, the fact that so many of the staff were on small part-time contracts meant that Joan, the co-ordinator of the area of work, could not bring staff together to function effectively as a team to achieve improvements in the department. Moves to a fully qualified workforce (see DfES, 2006) may increasingly constrain such flexibility in the next few years, as the investment that would-be teachers and colleges must make will increase.

The flexibility mentioned above remains a facet of work for many -perhaps most practitioners if they are to become more established in colleges. Whilst some welcome the chance to work in new fields, it is quite common to find practitioners working outside their 'comfort zone' in colleges, at least for some of the week, teaching a unit or module in an area they feel is beyond their field of expertise but also feeling they cannot or should not refuse to do so. John's example of this was teaching a unit on microprocessors when his own field was electrical engineering. John described how there was 'no one else to do it'. He found it '....a painful experience really because (I was)...so isolated, and (I was)... never quite sure whether (I was)... doing it right or not'. Paul provides another example, whereby in a context of falling student numbers and job vulnerability, he agreed to take on a leadership role - not in the area of photography, but for a whole range of media courses. As he put it, 'I ended up running media courses because someone had to, and I was one of the more flexible folk around. I ended up flexing myself out of what I like doing best'. Paul described a difficult series of negotiations in which he had to be very assertive in order to 'get back' to being a teacher and leader in the area of photography.

Professional engagement with flexibility is, therefore, reliant on a variety of experiences, sometimes risky, enhancing or strategic that impact on both tutor and college alike. Rachel, for example, provides an example of both the restrictive and expansive elements of this dimension. 
'I think as I get more into it \{the job\} I find it more and more difficult...To think of apportioning your time between what you think you're here for and what you actually end up doing'.

'The joys are of course the students that you can see you've, or feel you've made a difference with, the ones that have really come on. You know their confidence builds and so on. However you look at it you've got to have had some part in that.'... (Rachel).

Yet there are tensions around such 'trade offs' and avowed commitments to students that impact on professional identities in different ways as we go on to argue in the sections which follow.

\section{Being in FE: professional dispositions and practices}

If variety, informality, uncertainty and flexibility are regular features of the recruitment process and work situation of some FE practitioners, what ideas about professionality are present in colleges, and how important is this concept in the way that FE practitioners see their work? There was a great deal of complaint and disillusionment among participant tutors around some of the key attributes associated with professional status - with pay, regimes of audit and inspection, declining resources, lack of recognition of expertise, reduced autonomy through performance management and so forth. Yet these complaints did not come from a shared trade union or political position. They arose from strong commitments to teaching, to fostering student learning and development, to attending to learners' needs, and to self-development or learning as a professional. Time and again, the narrative data provided examples of tutor frustration that regimes of funding, management and audit/inspection prevented or made more difficult the exercise of professional judgement based on experience.

There are many theories and models that seek to define and understand what it is to be a professional. Traditionally, social science has approached questions about this in one of two ways. Firstly, a functionalist/consensus perspective characterises professions in terms of the attributes they might share as occupations and the functions they may serve in society. In this view the distinctive attributes of a profession may include a set of skills based on a body of theoretical knowledge, a clear route to qualification for practitioners, a code of conduct, an ethic of altruism and relatively high rewards. A second approach, which we might term an ideological/conflict perspective, sees professionalism as a strategy for establishing occupational dominance and for gaining a monopoly position, and examines the extent to which professionals' declared altruism is a mask for self-interest. These perspectives, or elements of them, continue to be visible in debates, but both are of limited utility because they represent attempts to understand why professions exist, rather than offering ways of understanding, in a detailed sense, the nature of professional knowledge and action. More recent analyses have moved closer to this approach, particularly in education, arguing that teachers are subject to intensification of work (Apple and Jungck, 1991); to de-professionalisation (Lawn and Ozga, 1988), to de-skilling or to a loss of control over the learning environment (Avis et al, 2002: see also Ashcroft and James, 1999; Campbell and Neill, 1994). Most recently of all, theorists have sought to understand how professionality engages and interacts with the audit culture, performativity and managerialism, and we return to this concern in the remainder of this chapter.

The participating tutors in the TLC project did see themselves as professionals, and they recognised and valued both the obligations and responsibilities that came with this identity. Whether or not it was currently felt, a sense of autonomy was valued highly - not for its 
own sake, but because of the necessity for continual adaptation to different learners and circumstances, the opportunity to deal with the unexpected and the serendipitous in student learning, and for solving problems. Many tutors also valued the opportunities they had for their own professional learning and action, an idea closely linked to autonomy. One such example is Florence, who described in her diary both her puzzlement and her joy about how well some of her teaching was going:

'So just a few words about the recent success of the classes. I haven't quite worked out the recipe. They approached the last topic a bit more independently, partly because I finally got round to setting it up that way, partly because I felt more comfortable with the idea that the group work would not be in French so long as it produced some French... They all took a mini topic from the main one of health and pursued that through their own reading/tapes/internet or simply through the textbook. Then, after a couple of sessions where group work sharing of information got shoved off the end of the lesson plan...I had a rather half-hearted go at getting the students to, first, speak with classmates who'd done the same topic (such things as eating disorders, smoking, sport, drugs etc) and then asked them to speak with at least two people who had done a different topic. This was the bit that amazed me. I went out of the room for a time, thinking about what I would do next if it wasn't going well. When I came in again, they were all speaking to each other in French (after a fashion) and they were thoroughly engaged in the activity'

This diary entry came from a tutor who, not long after writing it, had left FE in the wake of reductions in the contact hours allowed for the course which in her judgement made it impossible to teach properly (Colley, James and Diment, 2000).For another tutor, George, it was the 'wake of status' involved in a plethora of disconnected initiatives that impacted on his sense of professionalism. According to Wahlberg and Gleeson (2004) addressing biography is another way in which FE practitioners both define their professionalism and, at the same time, feel threatened by it. George, a Business Studies tutor (who has since left FE in 2004/5) points out that 'with the younger kids' he is now hardly a teacher, and feels more like a 'welfare officer'. This perceived shift from teaching to welfare arose in a number of interviews and meetings with him. It is seen as one of the consequences of an ill thought through and poorly funded social inclusion policy that has involved colleges in recruiting ever younger, more marginal and vulnerable students into a variety of vocational programmes that are inappropriate to their needs, or beyond their reach. The nature of such inclusion has become interpreted by practitioners as an unresolved tension between what the 'old' and the 'new' FE is about - between issues of teaching your specialised subject to motivated students and principles of social justice and equity - which are ideally though not necessarily the same thing in the turbulent world of FE practice. The issue here is more more than one of just biography. The 'wake of status' for George relates to uncertainties about a loss of professional identity and status that involves moving from being an accredited subject specialist( lecturer) with experience as an economist, to becoming a 'teacher' of lower grade courses toward a welfare or 'key skills' function (Ecclestone, 2000).

If such a response appears defensive it is also indicative of a reaction, among some FE tutors in this study, to risk and uncertainty in a sector increasingly pressurised by a reduction in resources, staffing and teaching hours. The TLC project itself generated a 'space' for participating tutors to reflect upon their practice and, to some extent, to research their pedagogic thinking. However, it is important not to confuse either what tutors value or the celebrated moments with what tends to pertain the rest of the time, or what 'goes without saying' in the normal practices of a learning site.

Overall, what was normally the case added up to a more depressing picture. Many tutors 
felt bound to an externally monitored cycle of recruitment, retention and certification linked to college funding, remuneration and quality measurement (cf. Bloomer, 1998). Rachel, for example, expressed the view that despite claims to the contrary, external inspection appeared more focused on teacher performance than on student learning. In her diary she described a lesson that had been observed by a senior colleague in preparation for a forthcoming Ofsted inspection:

'....a lesson in which I did absolutely no teaching but the outcomes were great in learning terms...It was amusing to be told that as no teaching had taken place, she (the senior colleague) could not give me adequate feedback on the 'lesson' as a whole, although she could not fault the activities, the students' commitment and dedication to the task, and the outcome was clearly that a high degree of learning had taken place. This latter point was endorsed by the students who said that they had enjoyed the activity and felt that they had learned a lot and it was helpful towards being able to complete a written assignment'

Rachel is questioning the idea that 'teaching' always means observable teacher talk or the directing of students in real time which, rightly or wrongly, a senior colleague had decided would need demonstrating to ensure success in a forthcoming inspection. In this example, a strong and specific notion of pedagogy is enshrined in the measurement of practice, but it is a notion that Rachel finds unrealistic, unhelpful and contrary to the evidence. There are further similarities with the case of Gwen's involvement with 'assessment only' NVQ provision. Confronted with students who needed learning support and who had weaknesses in the employer's view - and were at risk of losing their job - Gwen found it impossible to pretend that she was just an assessor. According to James \& Diment (2003) the separation of learning from competency based assessment placed tension on work based assessors such as Gwen whose working practices went well beyond her official contractual obligations. Examples include teaching and mentoring students in the workplace providing learning materials, giving her home telephone number to students in need, and negotiating with employers in support of students 'learning development'. Such interventions, described by James \& Diment as 'underground working,' ironically facilitated NVQ provision and, at the same time, rendered Gwen's detailed support for learners invisible. Whilst the emotional capital involved reveals skill, care and flexibility it can also be gendered and exploitative. Gwen, for example, was in no position to complain about something she should not have been doing officially in the eyes of the college (see James \& Diment, 2003). The question arises: what interpretations can be made about how practitioners handle such episodes, and what does it mean to be a professional in such circumstances?

\section{Compliance, Resistance and Mediation}

The analysis so far suggests that professional knowledge in FE is not fixed but situated in a recurring set of unstable conditions. From this perspective it is the ambiguities and tensions, the disruption and contradictions of lived professional experience, that create a multiplicity of identities and responses to external pressures. Paradoxically, marketisation and managerialism has had the effect of drawing attention to both its creative and restrictive practices as new cultures of professionalism are made possible. This is not, however, to exaggerate the progressive possibilities of such cultures or to underestimate the possibility their accommodation in managerial procedures. Rachel and Gwen's accounts reveal aspects of the dilemmas involved in creating their own room for professional manoeuvre and without being in a position to challenge the orthodoxy of inspection or competence based approaches. 
On first appearance Rachel, Paul, Gwen and George's reactions may appear as simple compliance, albeit reluctant. With more detailed analysis, however, we think that it is a mistake to see these and other tutors in the project as simply complying with instructions. Parallel research indicates the diverse ways in which professionals respond to market and managerial reform. At one level this manifests itself in creative and routinsed (willing) compliance, rule following or rule breaking, including the 'fabrication' of activities designed to meet targets that professionals do not necessarily believe in (Ball, 2006). At another, it involves mediation, 'trade-offs' and 'restorying' of professional identities in and against the audit culture (Stronach et al, 2002). Wallace and Hoyle (2006) suggest that research into the impact of educational reform on professional practice shows a high incidence of unintended consequences, ambiguity and wasted effort. In the light of this they advocate an 'ironic' perspective for understanding the situation of the managed professional. Referring to the concept of mediation, as a more useful characterisation than 'compliance', they argue that:

[Mediating professionals].... Express what we regard as principled infidelity. Infidelity follows from not fully adhering to policy-makers' expectations, and principled follows from attempting to sustain their professional values instead of embracing the alternative values under-girding reforms' (Wallace and Hoyle, 2006, p.12).

While there are strong parallels here with the concept of 'strategic compliance' (Gleeson \& Shain, 1999) the tutors in the TLC project also exhibited subtle mediation skills on the lines outlined by Wallace and Hoyle. Though apparently conforming, all found ways of providing learners with experiences that they valued and knew were valuable - beyond the syllabus and the timetable - what Robson et al (2004) call the 'value added' dimension of FE practitioners work. This insight provides a glimpse of the complexity of cultural change and is a reminder of the major problem with managerialism. It is important not to confuse managerialism with management and leadership. 'Managerialism is underpinned by an ideology which assumes that all aspects of organisational life can and should be controlled. In other words, that ambiguity can and should be radically reduced or eliminated' (Wallace, 2006, p.9). Wallace and Hoyle also argue that, by virtue of having backed a managerialist means to realising reform after reform, 'policy-makers have apparently failed to comprehend the nature of professional practice' (2006, p.10).

There is a strong affinity between a belief in managerialism and a continuing tendency to see professionalism as old-fashioned, as self-serving and as incapable of a flexible response to client need - and therefore as the wrong place to look for altruism or innovation. Although it has in the past had clearest political expression from socialists (perhaps most famously in George Bernard Shaw's play The Doctor's Dilemma), a more recent precursor of this view came from the Thatcher conservative government and was part of what Gewirtz 2002) refers to as the post-welfarist education policy complex and an associated manufacture of a new common sense. Gewirtz quotes Fergusson:

'Teachers were denigrated as self-interested and unaccountable. And while self-interest is normalized as part of the discourse of market relations, and elsewhere is celebrated as the engine of progress, it is seen in this instance as invalidating teachers' claims to professionalism. Other routes to breaking bureau professional power entailed the public questioning of the competency of teachers, allegations of the failure of the comprehensive system, the down-skilling of teachers' professional knowledge through the exclusion of theory in favour of more instrumental forms of initial training and in-service staff 
development...' (Fergusson, 1998, p.230).

This more or less concerted attack on an established concept of professionalism was also bound up with a general rising distrust of bureaucracy, a reassertion of the rights of the individual as customer, and the rise of the market and managerialism in the public sector. At the time of writing, a similar theme again finds expression in political thinking about the improvement of public services. One senior government figure has described how such improvement can only come out of a pincer-like movement in which the recent growth in top-down regulation through targets and standards is augmented by a new encouragement to bottom-up mechanisms for greater consumer or user 'voice'. In the middle of these two movements is an idea of the professional as simply someone who does a thorough job exactly in line with some sort of specification such as a service agreement (see Milliband 2006). However, the diversity of stakeholder interests and power in FE (employers, business, government, professional associations, communities and students) suggests that 'servicing' customer and consumer choice is a more complex process than it appears:for example, in terms of power whose voice and choice?

Our analysis of learning cultures shows that, crudely speaking, professionality cannot be eradicated by increasing prescription. Furthermore, rather than representing an obstacle to improvement, professionality is actually fundamental to it, because it is a crucial existing aspect of the learning culture, a facet of the reality of teaching and learning that is unrealistic to ignore. We think it is most helpful to conceive the professional habitus of tutors as a set of 'durable, transposable dispositions' (Bourdieu 1990, p. 53) that were often generated in different, prior circumstances and, at the same time, mediated by existing fields and communities of practice. As embodied facets of those different, prior circumstances or fields, there are limits to the synergy between these dispositions and the field that the tutors now find themselves within. In the case of Gwen, the relevant change in the field is the progressive segregation of learning and assessment, which might be termed the hallmark of the curriculum changes brought in by National Vocational Qualifications. In turn, this means that a key part of her professional capital - her pedagogical knowledge was no longer 'rated' so highly in the field (see James and Diment, 2003). By contrast, newly employed practitioners on 'assessment only' contracts occupy a more constrained, contractual relationship with the learners, and appeared to operate without the kind of dissonance experienced by Gwen (though she suggested their 'success rates' are not as high as her own).

It is important to note that an understanding of professionality, as the relationship between habitus and field, does not rely on the sort of normative grounds of everyday accounts. For example, in conventional terms, professionals who are critical of change can find themselves accused of 'golden ageism' (the idea that things were always better in the past), or of harbouring a self-interested lack of flexibility or resistance to change. Both these accusations are normative, in that they are pejorative. By contrast, we are arguing here that an established professional identity can be compromised simply by being located in a new field (much as a given amount of money can be worth little or nothing if taken into a country with a different currency). After this it is a separate empirical question as to whether things were better in the past or whether the individuals involved are reacting conservatively. Put at its simplest, an established professional identity can be compromised simply by being located in a new field (rather as a given amount of money can be worth little or nothing if taken into a country with a different currency). After this it is a separate empirical question as to whether things were better in the past or whether the individuals involved are reacting conservatively. 


\section{Professionality in a learning culture}

There can be little doubt that in fields like education, children's services, welfare and healthcare, the life of the professional, and what it means to be a professional, has become more complex and contradictory in recent decades.( Simmons et al 2006,Clarke 2006). Drawing on TLC-Project data Gleeson, Davies and Wheeler (2005) argue that FE practitioners work in one of the most 'market tested' sectors of public provision that constitute 'prototype' of more recent reforms that have 'radically altered democratic accountability in favour of government, business and corporate interests' (Gleeson et al, p. 447). A key aspect of their analysis questions the idea that there is a 'community of professional practice' in FE and argues that

'the challenge is to build one ...Building professional capacity in FE requires new theories of professionalism that can guide pedagogy and practice since...the pragmatism of FE practice - referred to by Scaife (2004) as the culture of the now is incapable of achieving such change alone' (Gleeson et al, p. 455)

Alongside the work of Shain(1999) and Bathmaker (2001), Gleeson et al state that FE professionals are usually seen as either subject to external reform or as active agents who can and do construct identity and meaning within their work. However, they argue, professional knowledge is generated through tensions that are experienced at the interface 'between external criteria of performance and those "ecologies of practice" (Stronach et al, 2002) that frame identity and reality making among FE professionals' (p. 455). This argument is supported by data from the TLC project that demonstrates the need for subtlety in any attempt to understand the role of professionality in contemporary practices. There are strong similarities with Wallace and Hoyle's argument, mentioned above, for a concept of mediation that helps us see beyond the cruder notions of compliance and noncompliance. However, where Wallace and Hoyle see grounds for optimism - if reforming policies can be made more 'temperate' (so that such policies acknowledge the essential ambiguity of the worlds of practice they seek to change) - Gleeson et al offer a more pessimistic prognosis. For them, the isolated and individualised're-storying' of practitioners cannot add up to the generation of stronger shared notions of professionalism. Though constantly faced with decisions about compliance or contestation, alongside opportunities to be creative (see Ranson, 2003; Stronach et al 2002), practitioners are located in a fragmented FE sector with little sense of its history where a 'culture of the now' predominates. Gaining a stronger sense of professionality requires a more fundamental shift in the relationships that produce it, perhaps through professionals enjoying higher levels of trust but also being more answerable to civil society, which, it could be argued, is the source of the authority implied by the term 'professional'. Perhaps a stronger sense of professionality could come from - the restoration of wider forms of democratic governance and accountability - which transcend market narratives and consumerist interests (Gleeson \& Knights, 2006). Thus, a cultural understanding of learning implies that professionalism does not simply occur in a social context but operates as a social practice and constitutes a highly contested process. This cultural understanding of learning draws attention to the significance of unequal power relations in $\mathrm{FE}$, in wider society and in individual learning sites.

The idea - or 'idealisation' - of a 'community of practice' of professionals in FE is challenged in another way within the TLC project. One common-sense view of professional work is that, on the whole, people gain experience over time and become more established, becoming located, as it were, more 'centrally'. The direction of movement implied here seems to fit with a popular contemporary theory of situated learning, the most 
well-known expression of which is that of Lave and Wenger (1991). Put simply, this social theory of learning does not dwell on the cognitive or mental processes that may be involved in learning, but on social arrangements and mechanisms. Novices enter a community of practice and engage at first in 'legitimate peripheral participation'. Over time, they move towards expertise and full membership and full participation. The theory is about both the social relations of learning and the conditions for the existence of any form of professional knowledge, and hence the existence of knowledgeable practitioners themselves (see Fuller et al., 2005).

Hodkinson and Hodkinson (2004) note that the communities of practice idea has become 'iconic' in recent years. However, along with some other established academic and policy constructs, the periphery-to-centre movement at the core of situated learning did not turn out to be a helpful framework when we looked across the professional trajectories of the FE tutors who participated in the TLC project. As Colley et al, writing just after the end of the fieldwork, put it:

'Of the 24 tutors $^{1}$ who participated in the project, only about a third remain committed to teaching in the sector. Three left FE to move into sixth form provision, two have become full-time managers and are no longer teaching, five have either quit their jobs or been made redundant, and five give accounts of themselves as marginalized, and are making serious efforts to leave FE (some have already reduced their hours to part-time)' (Colley et al, 200*, p. * JEP)

We do not claim that the 24 tutors in the TLC project were a classically representative sample of all the staff who teach in FE colleges in England. However, it is worth noting that the learning sites and participating tutors were chosen carefully, in a process of balancing the wishes of college managements with a need for purposive choices of case (Flyvbjerg, 2006) that would reflect the diversity of provision in the sector. The learning sites suggested for inclusion by colleges were not those they felt were particularly problematic, weak or vulnerable. Indeed, having worked for a time with the colleges, we learnt that many of the learning sites offered to the project had internal reputations for being relatively successful. This makes the figures quoted by Colley et al all the more poignant.

\section{Conclusion: toward a 'new discourse' of FE?}

Given the momentum of FE reform since Success for All (DfES, 2002) it could be argued that our analysis, so far, has been pessimistic and overcritical. In the period 2005/6 there have been no less than four major policy documents advocating major initiatives in the Learning and Skills Sector (Foster Report, 2005; DfES,2002;2004; 2005;2006; Leitch Report, 2006) signalling major reforms ahead. The tone set by the Review of Further Education carried out by Sir Andrew Foster (2005), advocating 'a new discourse' of FE (P3), had the following to say about the practitioners who work in Further Education.

\footnotetext{
"Almost a quarter of a million people are currently employed in FE Colleges across England. They are the most vital resource that FE colleges have. In the course of the review it was clear that focussed, committed and professional lecturers, support staff and leaders have transformed individual lives and made a real difference to local businesses” (p.73).
}

The same report goes on to note a series of existing measures to improve the quality and 
(continued) professional standing of the workforce and its leadership. These include reforms to teaching and learning overseen by the DfES Standards Unit, improvements to teacher training, the setting up of Life Long Learning UK to develop standards for the sector; and the 'embryonic' Institute for Learning, a new professional body for the LSS. The report recommends that in addition to these moves, 'a new national workforce development strategy be produced led by the DfES, founded on a fresh analysis of workforce needs' (p74). Tucked away rather less obviously is the suggestion that FE should become more employer led and return to its industrialroots, as a way of retrieving its reputation. The White Paper (DfES, 2006) contains a whole chapter geared toward 'A national strategy for teaching and learning in Further Education' in which plans are set out to lead a quality improvement strategy that involves new qualifications for teaching staff, materials and subject coaches. The Strategy would also 'support increasing personalisation' and a new drive to develop the workforce, including a requirement for Continuing Professional Development (DfES, 2006). With an FE Bill currently before Parliament and Government commitment to implementing the Leitch Report (2006), Prosperity for All in the Golbal Economy - World Class Skills, the scene looks set for a major expansion of FE in the wider context of the Learning and Skills Sector. Whether or not a demand led system led by the needs of employers - who have traditionally viewed skills as third or fourth order priorities in a' successful' low skill-low wage economy - remains in question (Gleeson \& Keep, 2004).

With over £2b earmarked for LSS expansion by 2010, much of it recycled from existing FE and adult learning budgets through the LSC to employers, the omens are not good. Already, lack of data held by the LSC about the LSS workforce coupled with inadequate funding by government for research into teaching and learning in FE, has been identified as an obstacle to the reform process (Coffield et al 2005;Foster, 2005). The danger, and many would put it stronger, - as a certainty - that across the continuing raft of reforms the narrowest notions of professionalism, accountability and control will continue to prevail. As a result the reservoir of expertise, experience and professionalism that we have identified so far will continue to pass by unrecognised and may disappear. Yet, as some of the basic research questions and data in the TLC project demonstrate, understanding professionalism in FE requires a subtle approach that takes cognisance of other major 'ecological' influences on the learning culture. A prevailing market and managerialist prospective allows only a restricted concept of professionality such as might be heard in connection with any high street service ('we offer only fully professional carpet cleaning', for example).The data and analysis that we have explored here illustrates how important an expanded concept of FE professionality remains, even in the face of repeated and pervasive challenges to the autonomy and scope for self-determination of its practitioners. If the current reforms directed toward improving teaching and learning are to be taken seriously, it is unrealistic to ignore the ways that professionality currently figures in practice and that ever greater doses of managerialism are unlikely to have the desired result.

\section{References (not yet complete!) \\ Ailey and Bailey 1997}

Ashcroft, K. and James, D. (1999) The Creative Professional London, Falmer Press

Alexiadou (2002)

Avis (?2006) 
Bourdieu, P. (1990) The Logic of Practice Cambridge U.K, Polity Press

Campbell, R.J. and Neill, S.R. St. J (1994) Secondary Teachers at Work London, Routledge

Colley, H., James, D. and Diment, K. (2007) JEP paper

Clarke

Department for Education and Skills, (2006) Further Education: Raising Skills, Improving Life Chances

Foster, A. (2005) Realising the potential: A review of the future role of further education colleges

Flyvbjerg, B. (2006) 'Five misunderstandings about case study research’ Qualitative Inquiry

Giddens (2000)

Gleeson and Mardle, (1980)

\section{Gleeson et al 2005}

Gleeson, D, Keep (2004)

Gleeson, D, Knights, ( ）

Guile and Lucas (1999)

Leitch (2006)

\section{Lucas 2004}

Lumby \& Simkins

Mackney, P. (2004) Opinion, The Guardian, May $5^{\text {th }}$, p.15

Miliband, D. (2006) 'Public services and public goods: lessons for reform' Speech by the Rt Hon David Miliband MP at the National School of Governance conference, Queen Elizabeth II Conference Centre, London, $6^{\text {th }}$ June 2006. See http://www.defra.gov.uk/corporate/ministers/speeches/david-miliband/dm060606.htm Accessed July 2006

Randle \& Brady

Shain, , Gleeson, D ()

Simmons et al

Venables

Wallace, M. and Hoyle, E. (2005) 'Towards Effective Management of a Reformed Teaching Profession' Paper presented to ESRC Teaching and Learning Research Programme thematic seminar series Changing Teacher Roles, Identities and Professionalism, Kings College, London, $5^{\text {th }}$ July. Available at www ***** (Accessed September 2006) 